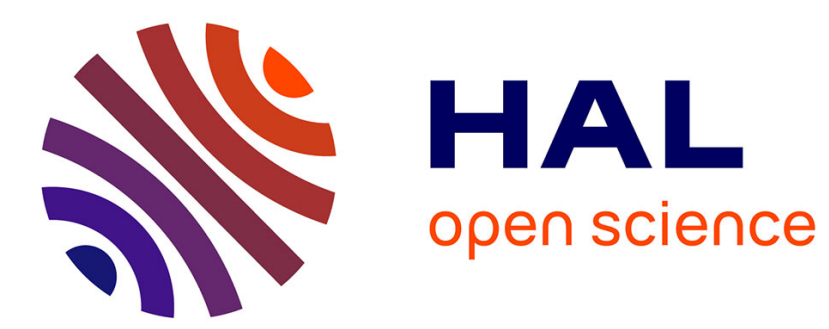

\title{
TWO DIMENSIONAL MATTER - SEARCH FOR THE MOBILE PHASE
}

\author{
H. Shechter
}

\section{To cite this version:}

H. Shechter. TWO DIMENSIONAL MATTER - SEARCH FOR THE MOBILE PHASE. Journal de Physique Colloques, 1977, 38 (C4), pp.C4-38-C4-43. 10.1051/jphyscol:1977406 . jpa-00217122

\section{HAL Id: jpa-00217122 https://hal.science/jpa-00217122}

Submitted on 1 Jan 1977

HAL is a multi-disciplinary open access archive for the deposit and dissemination of scientific research documents, whether they are published or not. The documents may come from teaching and research institutions in France or abroad, or from public or private research centers.
L'archive ouverte pluridisciplinaire HAL, est destinée au dépôt et à la diffusion de documents scientifiques de niveau recherche, publiés ou non, émanant des établissements d'enseignement et de recherche français ou étrangers, des laboratoires publics ou privés. 


\title{
TWO DIMENSIONAL MATTER - SEARCH FOR THE MOBILE PHASE
}

\author{
H. SHECHTER \\ Department of Physics, \\ Technion-Israël Institute of Technology, \\ Haifa 32000, Israël.
}

\begin{abstract}
Résumé. - L'effet Mössbauer a été appliqué à l'étude du processus de fusion par l'intermédiaire du facteur de Debye-Waller, et à la phase mobile pour $T>T_{\mathrm{c}}$. Cette méthode est décrite dans cet article, et des résultats antérieurs ainsi que des nouveaux résultats sont présentés. Les films qui sont physiquement adsorbés dans la région submonocouche de certains composés de fer et d'étain ont été déposés sur le plan de base de Papyex (graphite exfolié). Nous suggérons que l'effet Mössbauer peut être utilisé pour étudier ce type de diffusion car la mobilité latérale modifie la section efficace Mössbauer perpendiculaire.
\end{abstract}

\begin{abstract}
The Mössbauer effect has been applied to study the melting process via the Debye-Waller factor and to follow the mobile phase at $T>T_{\mathrm{c}}$. The method is described here and some previous and new results are summarized. The physisorbed films in the submonolayer region of some iron and tin compounds were deposited on the basal plane of Papyex (exfoliated graphite). It is suggested the Mössbauer effect can be used to study the type and magnitude of diffusion in the $2 \mathrm{D}$ liquid state since the lateral mobility affects the average cross section normal to the plane of the foils.
\end{abstract}

1. Introduction. - The Mössbauer effect has been recently applied to study monolayers. In particular, the nuclear hyperfine splitting and spectral shift was applied to identify film phases and their relation to their bulk phases $[1,2,3]$. Only recently has the recoilless gamma ray spectroscopy been applied to study phase changes of the films [4]. Here the Debye-Waller factor (the Mössbauer fraction) is used as well. The Mössbauer technique provides a direct measure of the nuclear mean square displacement.

More than a decade ago it was suggested theoretically that the Mössbauer technique can be used to study the diffusive motions of atoms in solids [5]. Since then it was applied on bulk solids [6].

In the study of two dimensional (2 D) films we expect to encounter a variety of regimes analogous to bulk matter, such as condensation into $2 \mathrm{D}$ liquid and solid. In the 19th century [7] phase changes were observed in monolayer films in semisoluble oil films on water. The $2 \mathrm{D}$ pressure $\phi$ was measured directly. $\phi-a$ diagrams are remarkably similar to the $P-V$ bulk diagrams [8]. For films on solid surfaces there are several thermodynamic quantities more suitable than $\phi$ for direct measurements giving strong indications of phase changes in two dimensions, and three phases, two dimensional solid, liquid and gas - were observed by Thomy and Duval [9] in krypton and xenon on graphite. The theory of interacting adatoms is well documented in the literature [10].

Early attempts to identify melting in monolayer films involved specific heat measurements $[10,11,12]$. It happens that in bulk melting there is usually a dramatic change in fluidity simultaneous with the observed loss of spatial long range order. However, this association is not known for the case of films.

A series of pronounced heat capacity peaks in ${ }^{4} \mathrm{He}$ were observed. The transition, unlike that of the $3 \mathrm{D}$ melting [11] is not of a first order nature. Similar experiments were done on ${ }^{3} \mathrm{He}[10]$. The melting process was studied by $\mathrm{nmr}$ [13] for ${ }^{3} \mathrm{He}$ filmed on graphitized carbon black. Unfortunately, N.M.R. can not distinguish between first and second order.

In all the mentioned studies the change in fluidity following the melting process were always presumption but not proven. It had been accepted for many years that the $2 \mathrm{D}$ crystals could not exist above $T=0$ [14]. But it was pointed out [15] that the weak logarithmic dependence on size [10] allows a finite range of temperatures, and a laboratory size crystal could exist.

The theories are confronted when applied to the problem of melting. The relevance of the 
mean square displacement to the melting of a $2 \mathrm{D}$ solids would seem to follow from the semiempirical three dimensional Lindemann's melting law, $\theta_{\mathrm{D}}=$ const. $\left(T_{\mathrm{m}} / m v^{2 / 3}\right)^{1 / 2} . \quad \theta_{\mathrm{D}}$ is the Debye temperature, $v$-the atomic volume and $m$-the mass). When similar arguments are applied to the two dimensional case, the mean square displacement is not independent of distance $n d$, $\left\langle r^{2}\right\rangle_{2 \mathrm{D}} \propto T \log (n d)$, as it is in the $3 \mathrm{D}:$ It increases monotonically with atomic separation. Then at intermediate temperatures the local environs of an atom are solid while distant regions are liquid. To overcome these problems a new form of order, a directional order was suggested [16] distinct from positional order : In spite of the $2 \mathrm{D}$ mean squared displacement divergence, a $2 \mathrm{D}$ lattice retains long range directional order above $T=0$; there is a correlation between the direction of a local lattice vectors at different locations in the crystal. However, for completely harmonic forces this model predicts a long range directional order at any temperature.

A later model is based on the dislocation model of melting $[10,17]$, it is supposed that a liquid close to its freezing point has a local structure similar to that of a solid but that in its equilibrium configurations there is some concentration of dislocations which can polarize and stretch under the influence of a shear stress. At some temperature $T_{\mathrm{m}}$ the average length of dislocation diverges; then there is a complete loss of elastic restoring force; the substance melts. For $2 \mathrm{D}$ it yields a melting temperature $T_{\mathrm{m}}=(2 \pi)^{-2}\left(m k / 8 h^{2}\right) a \theta_{\mathrm{D}}^{2}$. This fits the ${ }^{4} \mathrm{He}$ results, with less success for ${ }^{3} \mathrm{He}$. However, it is far away for more complicated molecules. Here, $k$ is the Boltzman constant, $a$ the area per molecule.

There are as well other puzzles in the melting of films such as the sharpness of the transition (the order) which may have to do with the substrate-adatom interaction.

This search of the two dimensional mobile phase is based on the Mössbauer spectroscopy. We report here on the adoption of the early suggested principles for bulk [5] as applied for monolayers. It is a summary report of the state of the art today. The results discussed here were collected mainly from two works, a report on melting of butadiene iron tricarbonyl monolayers [4] and one of the melting of tetramethyltin, which is still in progress.

2. Experimental details. - 2 a SAMPLES. - 1,3butadiene iron tricarbonyl (BIT), $\mathrm{C}_{4} \mathrm{H}_{6} \mathrm{Fe}(\mathrm{CO})_{3}$ and tetramethyltin (TMT), $\mathrm{Sn}\left(\mathrm{CH}_{3}\right)_{4}$. These materials were chosen for this study due to some convenient properties, such as reasonable vapor pressure at room temperature, chemical stability; they include Mössbauer isotopes, ${ }^{57} \mathrm{Fe}$ and ${ }^{119} \mathrm{Sn}$. The BIT is a stable diamagnet, liquid at room temperature with a vapor pressure of about 1 torr. It freezes at $19^{\circ} \mathrm{C}$ (boils at $48^{\circ} \mathrm{C}$ ). Its molecular weight is 193.97 , density $\left(20^{\circ} \mathrm{C}\right)=1.5788$. Its molecular area (obtained from density and from vapor pressure isotherms) is $41.0 \AA$. Its structure is reported elsewere [18-21]. Mössbauer studies on the bulk are documented [21]. The non-magnetic TMT [2] is a liquid at room temperature with vapor pressure of about $92 \mathrm{~mm}$ at room temperature. It freezes at $-53^{\circ} \mathrm{C}$ (boiling: $78^{\circ} \mathrm{C}$ ). The specific gravity is 1.2913 and the molecular weight 178.84; The molecular area is $37.2 \AA^{2}$.

2.b SAMPLE PREPARATION. - The adsorbent for the BIT was Papyex [22], an exfoliated graphite similar to Grafoil, with primarily basal plane surfaces exposed for adsorption. Sixteen grams of Papyex sheets formed a stack that fits into a specially designed Mössbauer cell. The stack was pumped at $975^{\circ} \mathrm{C}$. The adsorption area of $340 \mathrm{~m}^{2}$ was determined by $\mathrm{N}_{2}$ vapor pressure isotherms. The standard gas-volume necessary to complete a coverage of one monolayer of the studied samples were determined from the known adsorption area and charged volume of gas. The stack was then charged isothermally at room temperature to the desired coverages $(0.3 ; 0.6 ; 1.0$ monolayer $)$. Mössbauer spectra were then recorded at various film coverage temperatures, with the $\mathbf{k}_{\gamma}$ parallel and perpendicular to the graphite basal planes. The thickness of the Papyex in both directions, determined from the amount of atomic absorption of 6 and $14 \mathrm{keV}$ of the ${ }^{57} \mathrm{Co}$ radiation, was found to be the same in the two directions within $6 \%$. The TMT was adsorbed on Grafoil with the same treatment.

2. c THE RADIATION SOURCES. $-25 \mathrm{mC}$ of ${ }^{57} \mathrm{Co}$ in rhodium matrix was used for the BIT: "The source had $0.099 \mathrm{~mm} / \mathrm{s}$ linewidth. A tin source was used for the TMT molecule; the ${ }^{119} \mathrm{Sn}$ was embedded in calcium stannate with a linewidth of $0.377 \mathrm{~mm} / \mathrm{s}$. A conventional Mössbauer on-line spectrometer was used.

3. Data. - a. MÖSSBAUER SPECTRA. Figures 1 and 2 show examples of Mössbauer spectra of one monolayer of BIT (Fig. 1) and TMT (Fig. 2) at various temperatures with the directions of observation (directions of $\mathbf{k}_{\gamma}$ ) perpendicular (a) and parallel (b) to the plane of the graphite. The solid line is a computer least squares fit of Lorentzians. In some cases the line was different from Lorentzian and the spectral intensity was computed numerically. Inspite of the reasonable statistics $\left(10^{6}\right.$ counts per channel) the statistical spread of the data is disturbing due to the extremely low Mössbauer fraction. There is no effect above $230 \mathrm{~K}$ for BIT even in the bulk. The $f$-factor (Mössbauer fraction) of the film absorbers, $f^{\prime}$, was obtained from the dimensionless area $A=2 B / \pi f \Gamma$. $B$ is the background corrected measured spectral 


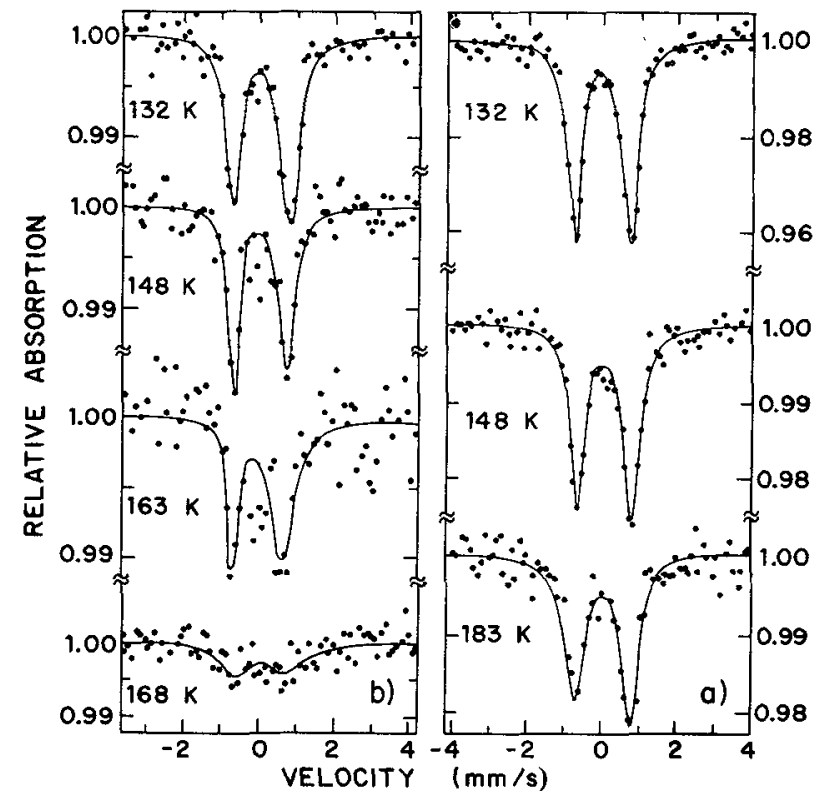

FIG. 1. - Mössbauer spectra of BIT adsorbed on Papyex at different temperatures for one monolayer coverage. $\mathbf{k}_{\gamma}$ is perpendicular (a) and parallel (b) to the Papyex sheets.

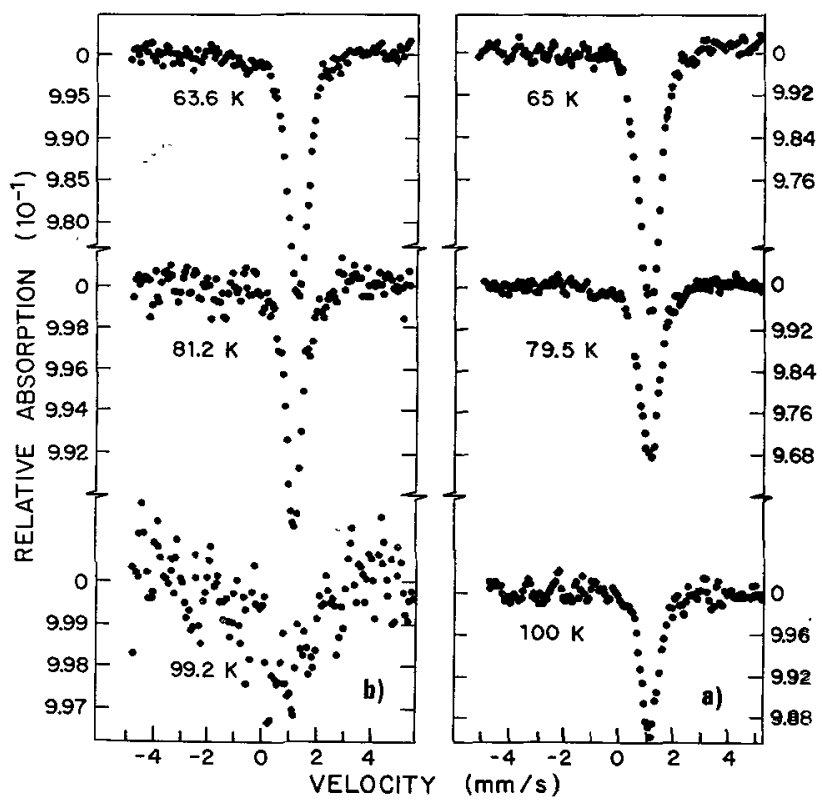

FIG. 2. - Mössbauer spectra of TMT adsorbed on Grafoil at different temperatures for-one monolayer coverage. $\mathbf{k}_{\gamma}$ is perpendicular (a) and parallel (b) to the plane of the Grafoil sheets.

area, $\Gamma$ is the natural linewidth of the source, $f$ is the fraction of the source, $f^{\prime}=A / n \sigma_{0}$, where $n$ is the number of absorber nuclei per square $\mathrm{cm}, \sigma_{0}$ is the on-resonance cross section.

Figures 3 and 4 show the on-resonance absorption versus the ambient temperature for $\mathbf{k}_{\gamma}$ parallel and perpendicular to the graphite basal plane. The on-resonance absorption in figures 2 and 3 was made in such a way that below $T_{\mathrm{m}}$ it describes $f^{\prime}(T)$. It should be noticed that even though the

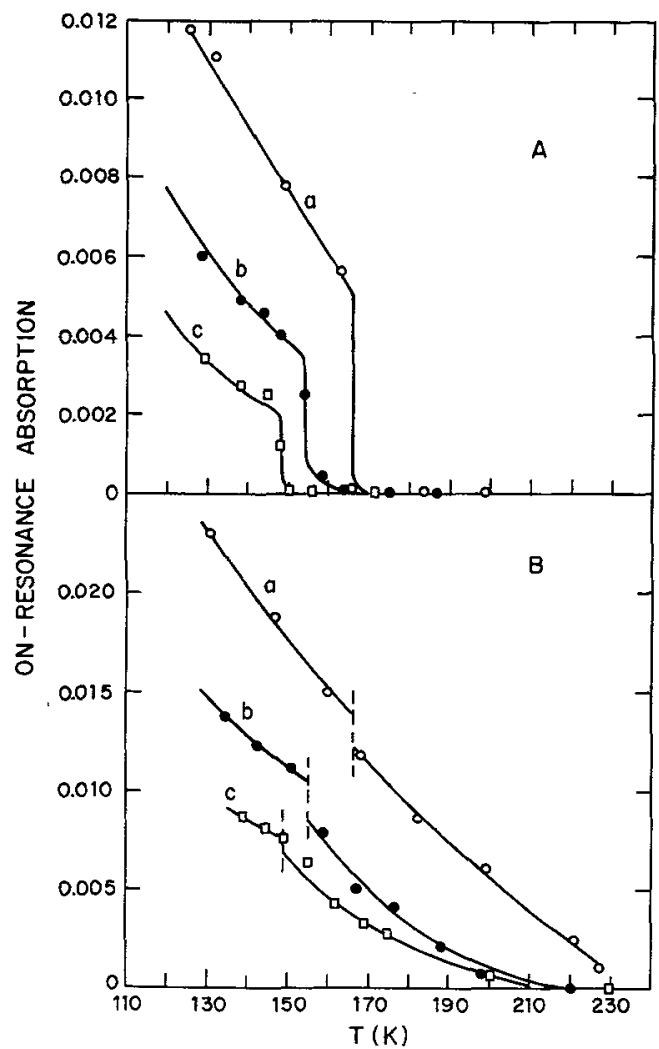

FIG. 3. - On-resonance absorption fraction of BIT adsorbed on Papyex for different temperatures : (A) for $\mathbf{k}_{\gamma}$ parallel, and (B) for $\mathbf{k}_{\gamma}$ perpendicular to the plane of the Papyex. a, b, c are for 0.3 , 0.6 and 1.0 monolayer.

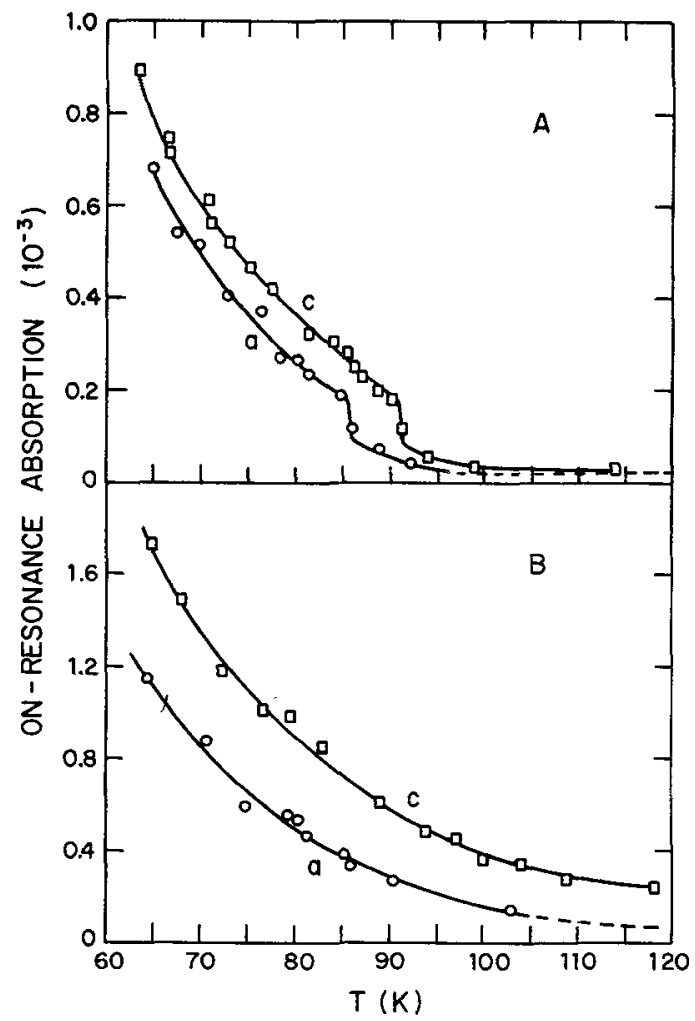

FIG. 4. - On-resonance absorption fraction of TMT adsorbed on Grafoil for various temperatures : (A) for $\mathbf{k}_{\gamma}$ parallel, and (B) for $\mathbf{k}_{\gamma}$ perpendicular to the plane of the Grafoil. a, $\mathrm{c}$ are for 0.3 and 1.0 of a monolayer. 
Mössbauer lines disappear when observed with $\mathbf{k}_{\gamma}$ parallel to the plane whereas the intensity is still considerable when $\mathbf{k}_{\gamma}$ is perpendicular to the basal plane. The results show that for the BIT the $f^{\prime}$ and the $T_{m}$ are lower for higher coverages whereas for the TMT, in contrast to the first, $f^{\prime}$ and $T_{\mathrm{m}}$ are lower for lower coverages.

4. Discussion. - The comments on the results are related to two regions: Below and above the melting temperature $T_{m}$. It has been shown that the diffusion broadens the Mössbauer line beyond the velocity window $[5,6]$. In bulk, liquid, or crystal over a limited temperature range unlike crystalline jumpdiffusion, the mobile diffusion is continuous [6] in good agreement with the theory [5]. Following the general expression for a classical fluid resonance cross-section $\sigma_{\text {res }}[5]$ and introducing a solution for the two dimensional classical liquid diffusion equation it can be shown that :

$$
\sigma_{\text {res }}=\frac{\sigma_{0}}{2} \mathrm{e}^{-2 w_{\mathrm{a}}}\left(1+\frac{h D k^{2}}{\pi \Gamma} \sin ^{2} \theta\right)^{-1 / 2}
$$

Here $W_{\mathrm{a}}$ is the Debye-Waller factor for the absorber, $D$ is the diffusion coefficient. The $D$ is in fact the mean square displacement per unit time ; the relevant motion is just the component of the displacement along the direction of propagation of the gamma rays $\mathbf{k}_{\gamma^{\text {. }}} \boldsymbol{\theta}$ is the angle between $\mathbf{k}_{\gamma}$ and the normal to the plane. It is possible therefore in principle to eliminate diffusional broadening by measuring in the surface-normal direction. The situation is complicated, however, by the fact that the Grafoil (and probably the Papyex) has its crystallites oriented only partially preferentially with basal planes parallel to the planes of the sheets. But the distribution of orientations in Grafoil as determined by neutron diffraction [22] is, for $50 \%$ of the crystallites a symmetric distribution of $c$-axis directions about the average normal to the surface of the sheets with $30 \%$ full width at half maximum. The other $50 \%$ have random orientation. The outcome is that the component of $\left\langle r^{2}\right\rangle_{r>r_{m}}$ along the normal to the surface due to this misalignment should attenuate the effect observed in the direction of the normal of the Papyex sheet. The almost perfect behavior in this direction as seen from the results presented in figures 3 and 4 seems to indicate that this sample of Papyex has considerable better average orientation. Yet, the results give clear signs of a melting transition. However, recently the misalignment of the Grafoil has been questioned $\left({ }^{1}\right)$ but it is not clear whether this better distribution is true in all samples.

(') Dash, J. G., Stern, E. A., Private communication. Recent EXAFS experiments on $\mathrm{Br}_{2}$ adsorbed on Grafoil show a well defined position of the molecule when examined perpendicular and parallel to the surface. Those results suggest that the Grafoil is extremely well alligned and the neutron results of Ref. [22] can be interpreted differently.
There is a recent development of perfectly alligned exfoliated graphite, prepared from single crystals (UCAR/2 YX [22]) which give, may be, hope to more precise directional studies.

Below $T_{\mathrm{m}}$ the two dimensional solid can be described by a simple Debye model. If $N$ is the number of atoms in the crystal, $n=N^{1 / 2}$, the mean squared displacement of the molecules in such a crystal monolayer is given by

$$
\left\langle r^{2}\right\rangle_{T}=\frac{h^{2} T}{\pi^{2} m k \theta_{\mathrm{D}}^{2}} \log n
$$

The Mössbauer fraction of the monolayered absorber is

$$
f^{\prime}(T)=\mathrm{e}^{-2 W_{\boldsymbol{\alpha}}}=\mathrm{e}^{-4 \pi\left\langle r^{2}\right\rangle} \boldsymbol{T}^{/ \lambda^{2}}
$$

$f^{\prime}(T)$ is determined experimentally.

The dependence of the positional order on the temperature and on the size of the system should cause the $2 W_{\text {a }}$ factor to vary smoothly as $T \log n$. The loss of directional order may occur within a narrow temperature interval (first or second-order melting transition). As a matter of fact, when the BIT or TMT molecules are concerned we can not say much about $\log n$. We can merely speculate. For instance, if Grafoil is composed of uniform crystals of about $100 \AA$ in diameter [23] - at full coverage and, say, the BIT molecule with the area of $41 \AA^{2}$, $N=10^{4} / 41=244$ and thus $n=16$. The BIT results show that the Debye temperature, $\theta_{\mathrm{D}} \cong 60 \mathrm{~K}$ (close to that of TMT) - is independent on the coverage. However, we don't know much about the formation of these films ; for the BIT, the Mössbauer fraction measured in perpendicular to the film is larger than that taken in parallel to the surface. That means that the adsorption forces are larger than the intermolecular interaction. Then when the coverage increases and admolecules come closer to each other (and may form patches) the molecule is more isolated energetically from the substrate and thus the Mössbauer fraction is smaller. For the trimethyltin molecule, however, the $f^{\prime}$ increases with coverage. A Mössbauer experiment with krypton adatoms is in progress and it is expected that the results will help the understanding of the $\log n$ term.

At $T_{\mathrm{m}}$, the spectral intensity for $\mathbf{k}_{\gamma}$ parallel to the surface drops suddenly (Fig. 4): The behavior is similar to that obtained in a $3 \mathrm{D}$ first order phase-transition from the immobile to the mobile state. As a result from the Kosterlitz and Thouless' model [17] the melting temperature is given by

$$
T_{\mathrm{m}}=(2 \pi)^{-2} m k a \theta_{\mathrm{D}}^{2} / 8 h^{2} .
$$

When applied for the BIT molecule the melting temperature predicted is higher by a factor of 10.0 is $\theta_{\mathrm{D}}$ wrong, or is the real system much more complicated? 
The area per molecule, $a$, decreases with increasing coverage. Hence $T_{\mathrm{m}}$ is expected to reduce with increasing coverage if $\theta_{\mathrm{D}}$ does not change. It does for the BIT. Nevertheless it increases with increasing coverage for TMT, like the nitrogen and the nobel gases. The krypton and xenon Mössbauer experiments may solve this mistery as well.

5. Summary. - An attempt was made here to introduce the Mössbauer spectroscopy as a tool applicable for surface study. In our desire to enhance its versatility the solid-mobile transition was represented where the search was extended into the mobile phase.

As a matter of fact, the Mössbauer technology has found its use in identification and classification of solid films deposited on various substrates. As early as 1970 physisorbed krypton was studied [1] by the Mössbauer effect. Later, studying the Debye-Waller factor normal to the graphite basal plane the results were used to estimate the binding energy of the adsorbed $\mathrm{Sn}\left(\mathrm{CH}_{3}\right)_{4}, \mathrm{SnCl}_{4}$, and $\mathrm{SnI}_{4}$ molecules [2].

The advantages of Mössbauer spectroscopy for physisorption include the relative ease of measurement of the Debye-Waller factor of small numbers of molecules. Unfortunately although many Mössbauer resonant isotopes are known, almost all are in atomic species which tend to form chemical bonds. Chemical compounds can then be used.

With the unique characteristics of Grafoil and Papyex it is possible to study the thermal shifts, quadrupole splittings and magnetic hyperfine interactions of suitable nuclei in a variety of molecular environments. Such an application was recently made [3] when $\mathrm{FeCl}_{2}$ molecules were deposited on Grafoil with coverage in the submonolayer region $(0.2$ and $u p)$ and the developement of the electric field gradient toward that of the bulk was used to study the variety of $2 \mathrm{D}$ phases registered on the graphite basal plane.

This newly acquired technique may soon be of a great aid in the understanding of surface problems.

Acknowledgments. - I would like to thank Professors R. E. Peierls, R. Ingalls, J. Suzanne and S. Bukshpan for their contributions to the works cited here. The help of $\mathrm{R}$. Brener in the $\mathrm{Sn}\left(\mathrm{CH}_{3}\right)_{4}$ study is greatly acknowledged. I am particularly indebtful to Prof. J. G. Dash who taught me the art of monolayer films and has been inspiring me since.

\section{References}

[1] Bukshpan, S., Ruby, S. L., Bull. Am. Phys. Soc. 16 (1971) 850.

[2] Bukshpan, S., Sonnino, T., Dash, J. G., Surf. Sci. 52 (1975) 466

[3] Shechter, H., Dash, J. G., Mor, M., Ingalls, R., Bukshpan, S., Phys. Rev, 14 (1976) 1876.

[4] Shechter, H., Suzanne, J., Dash, J. G., Phys. Rev. Lett. 37 (1976) 706

[5] Singwi, K. S., Suolander, A., Phys. Rev. 120 (1960) 1093.

[6] Ruby, S. L., Love, J. C., FlynN, P. A., Zabrowsky, B. J., Appl. Phys. Lett. 27 (1975) 322 ; CRATG, D. P., Sutin, N., Phys. Rev. Lett. 11 (1963) 460 ; Boyle, A. J. F., Bunbury, St. P., Edwards, C., Hall, H. E., Proc. Phys. Soc. London 77 (1961) 129.

[7] Adam, N. K., The Physics and Chemistry of Surfaces (Oxford University Press, Clarendon, London and N.Y.) 1941

[8] Hawkins, G. A., Benedek, G. B., Phys. Rev. Lett. 32 (1974) 524.

[9] Thomy, A., Duval, X., J. Chim. Phys. Phys. Chim. Biol. 67 (1970) 1101 ; and Duval, X., ThомY, A., C. $R$ Hebd. Séan Acad. Sci. Paris 259 (1964) 4007.

[10] Dash, J. G., Films on Solid Surfaces (Academic Press, N.Y.) 1975 .

[11] BreTZ, M. et al., Phys. Rev. A 8 (1973) 1589 ; Hering, S. V., VILCHES, O. E., Monolayer and Submonolayer He-Filmes (Edit. by Daunt and Lerner, p. 1, Plenum Press, N.Y.) 1973; and ElgIN, R. L., GoodsteIN, D. L., Ibid, p. 35 .
[12] Huff, G. B., Dash, J. G., J. Low Temp. Phys. 24 (1976) 155 .

[13] Rollefson, R. T., Phys, Rev. Lett. 29 (1972) 410.

[14] Peierls, R. E., Ann. Inst. Henri Poincaré 5 (1935) 1771.

[15] GuNTHER, L., Phys. Lett. 25A (1967) 649.

[16] Mermin, N. D., Phys. Rev. 176 (1968) 250

[17] Kosterlitz, J. M., Thouless, D. J., J. Phys. C. (Solid State Physics) 5 (1972) 124 ; and 6 (1973) 1181.

[18] Hallam, B. F., Pauson, P. L., J. Chem. Soc. (1958) 642 Glossom, Nozinowski, Clifford, J. Org. Chem. 22 (1957) 598; Tables of Organometallic Compounds Vol. I, 2nd Ed. (1966).

[19] Green, M. L. H., Pratt, L., Wilkinson, G., J. Chem. Soc. (1959) 3753.

[20] Mills, O. S., Robertson, G., Acta Crystallogr. 16 (1963) 758

[21] Collins, R. L., Petrt, R., J. Am. Chem. Soc. 85 (1963) 2332 ; Collins, R. L., Travis J. C., Mössbauer Effect Methodology Vol. III, p. 123, 1967.

[22] The Papyex is produced by Le Carbone Lorraine, 45, rue des Acacias, 75821 Paris Cedex 17, France ; the Grafoil and the UCAR/2YX - by Union Carbide Corp., 270 Park Avenue, N.Y. See also KJEMS, K. J., PASSEL, L., Taub, H., Dash, J. G., Novaco, A. D., Phys. Rev. B 13 (1976) 1446.

[23] Dash, J. G., Suzanne, J., Shechter, H., Peierls, R. E., Surf. Sci. 60 (1976) 411. 


\section{DISCUSSION}

J. TABONY. - The diffusion constants you report are rather long $\left(10^{-6} \mathrm{~cm}^{2} \mathrm{~s}^{-1}\right)$ compared with other values reported today $\left(10^{-4} \mathrm{~cm}^{2} \mathrm{~s}^{-1}\right)$ for $2 \mathrm{D}$ liquids. Since the time scale of your experiment $\left(10^{-7} \mathrm{~s}\right)$ is also much longer than that for quasi-elastic neutron scattering, there seems to be the possibility that you may not be measuring fast diffusion parallel to the surface, but a slower diffusion perpendicular to the surface or even interparticle diffusion.

H. SHECHTER. - I reported a diffusion constant of a certain material at a full monolayer, at a constant temperature. I cannot comment on the range possible in other films. I think, however, that the angular dependence of the intensity of the
Mössbauer line in this case does indicate that the diffusion is mainly lateral. See my answer to Prof. McTague's question.

J. P. McTague. - Could you give me an idea of the time scale your measurements are sensitive to ?

H. SHECHTER. - The experiment measures times in the range $\sim 10^{-8} \leq t \leq 10^{-7} \mathrm{~s}$. Atomic diffusion times (i.e. for motions $\sim \lambda_{\gamma} \approx 0.8 \AA$ ) which are longer than $10^{-7} \mathrm{~s}$, are slow and those shorter than $10^{-7}$ are fast... Since the line width increases from its minimum value to a value greater than we can measure in a temperature interval of $1 \mathrm{~K}$, we know that the diffusion time increases from $t>10^{-7} \mathrm{~s}$ to $t<10^{-8} \mathrm{~s}$ in that interval... 